\title{
Issues on Future of Offshoring and Global Sourcing
}

\author{
Michela Pellicelli \\ University of Pavia, Pavia, Italy
}

\begin{abstract}
In recent years, outsourcing strategies have undergone a profound evolution, moving from being a pure make or buy tactical decision to becoming part of strategy. By tradition, firms originally considered outsourcing as a solution to short-term problems, such as a sudden or unexpected increase in demand, an interruption in plant or equipment functioning, or the launch of a new product. Today firms consider outsourcing as a network of stable agreements with specialized suppliers as part of a long-term strategic perspective. The tendency is to attain offshoring and global sourcing. However, researchers are unanimous in recognizing that there are many obstacles to adopting a long-term outsourcing and offshoring strategies. They have also been heavily criticized by governments (the U.S. and Europe in particular) as recognized as a cause of further weakening national economies. Recently, some studies and research found that the large multinational corporations, mainly in the United States, are moving their production back or considering it such a strategic decision in the near future. So what is the future for offshoring and global sourcing?
\end{abstract}

Keywords: outsourcing, offshoring, global sourcing, outsourcing strategies

\section{Achieving Competitive Advantages With Outsourcing Strategies}

In the new millennium, outsourcing and offshoring have by now become the standard for firms constantly in search of new frontiers in order to compete worldwide. From a theoretical point of view, the propensity of firms to adopt outsourcing is a function of the difference between the price of the external producer (the marginal cost of the external service market) and the marginal cost of in-house production (Williamson, 1989; Chalos, 1995; Roodhooft \& Warlop, 1999). According to Quinn and Hilmer (1994), from a strategic perspective, outsourcing allows management to optimize the firm's resources in four principal ways: (a) by maximizing the output from internal resources by concentrating investment and effort on what the firm does best; (b) by developing the core competencies by setting up barriers against present or future competitors who might try to enter the firm's areas of interest, thereby protecting its competitive advantages; (c) by utilizing the investments of outside firms, as well as their innovations, skills and specializations, which could be maintained in-house only through continuous investments and innovation; (d) by reducing the risks from rapidly changing markets and fast-evolving technology; an outsourcing strategy shifts the risks involving technological updating and R\&D costs outside the firm, thereby shortening the production cycles and making responses to customer needs more flexible and rapid.

The outsourcing drivers can be grouped into three large categories, each of which includes four significant

Michela Pellicelli, assistant professor, Ph.D. in Business Administration and Management, Department of Economics and Management, University of Pavia, Pavia, Italy.

Correspondence concerning this article should be addressed to Michela Pellicelli, Department of Economics and Management, University of Pavia, Via San Felice 5, 27100 Pavia, Italy. E-mail: michela.pellicelli@eco.unipv.it. 
drivers (Pellicelli, 2009a, 2009b): (1) cost reduction (reduction in operating costs, reduction in investments, variability of costs, managing downsizing), (2) access to competencies (focusing on the core business, access to technologies, access to skills, integration of competencies), (3) increase in revenues (improved reactivity, speed to market, quality improvement, customer response time).

There are several strategies that consider outsourcing or offshoring as policies for achieving or consolidating competitive advantages and the most important are the followings. An initial strategy favoured by outsourcing is what allows firms - by adopting the opposite approach to mass production as a means of reducing unit production costs - to segment the vertical production chain into a lean production process, thereby allowing the firm: (a) to reduce the preparation times of machines and complex systems, (b) to increase the use of machines and plants through better planning, (c) to facilitate quality control over all the stages in the production process. On one hand, the reduction of costs is facilitated by increases in the market share, and thus by aggressive policies regarding pricing, promotions, and distribution. On the other hand, such policies are possible only if the firm can produce products customers perceive as having high value but at lower production costs. This interaction is perceived through the ratio between customer defection rate and unit costs. Customer defection is an indirect indicator of the loyalty of customers, which in turn depends on the firm's ability to satisfy its clientele with production that exhibits the maximum ratio between utility and cost for the customer. This means that the reduction of the customer defection rate is fundamental for acquiring significant cost economies. If a function or phase of the vertical chain is outsourced, it is indispensable for the firm to closely control the quality of the production of components, even more so if this involves finished products.

\section{Offshoring and Global Sourcing Strategies}

Thanks to production specialization, at each production level, outsourcing can divide a growing complexity into more easily manageable parts. With the development of the merchant marine and container ships and the increasing railway modalities as the faster Trans-Asian lines (Dalla Chiara, Pellicelli, \& De Bonis., 2012; Dalla Chiara \& Pellicelli, 2010, 2011), globalization has begun to separate the geography of production from the geography of consumption (Mella, 2007). However, with the continued industrialization in some emerging countries, China and India in particular, outsourcing has taken on new forms-with the delocalization of entire production processes - and in many firms is at the centre of choices regarding how best to compete.

Global outsourcing and offshoring are processes that best illustrate this tendency. Even the object of outsourcing is changing, with the birth of firms capable of stipulating contracts for the supply of outsourcing services on a global scale. Since for each outsourcee, the strategic intent is always to increase economic efficiency and profitability, outsourcing and offshore activities are based on a single strategy, called offshoring, whereby national firms that outsource becomes multinational ones. Thanks to their presence in several countries, multinationals can undertake a quite vast array of decision-making policies: producing internally or externally, as well as decisions regarding the countries whose firms are to serve as outsourcers. For such firms, offshoring widens their field of application and evolves into a global sourcing strategy according to which the multinationals must develop a global view of the international supply of outsourcers in order to be able to rapidly shift offshoring from one country to another. Offshoring and global sourcing may seem like strategies and problems of the modern globalized economy, but in reality, according to Kotabe and Helsen (1998), the shifting of production from one geographical area to another in the search for comparative advantages from 
location is not really that recent. Over the last two decades, several trends have further spurred outsourcing, making the links between firms located in different countries more widespread and stable, thereby favouring stable cooperation among them in an ever wider production network. Innovations and changes in the infrastructures of international exchanges, progress in communications and transport, and new financial instruments have made the move to offshoring simpler. This tendency has made it easier for firms that utilize components to obtain products from foreign suppliers on more favourable terms than those in-house production would allow (Pellicelli, 2006, 2009a, 2009b). The spread of just-in-time has strengthened the long-term relations between suppliers and customers and handed over more responsibility to management for purchases, shifting decision-making toward the top of the organization.

In this context, outsourcing and offshoring have evolved: From a tactical decision, they have increasingly become a strategic one, opening up to global markets and favouring the development of global sourcing. A growing number of firms have outsourced entire production processes by building production plants in various parts of the world which are closely controlled through various partnership forms. The increase in the demand for components in new geographical areas has favoured the birth of component producing firms that initially were local and then became global. The long-term relations with these producers have, in turn, favoured the transfer of R\&D to the most disparate geographical areas, giving rise to what is tantamount to a world of firms without borders. The choice among the various types of sourcing is particularly complex for a multinational company since, in terms of convenience, it is necessary to consider not only the drivers of production costs but also the trends in exchange rates, the efficiency of transport and communications infrastructures in the various countries, economic transparency, safety, the economic and cultural environment, and the attitude of governments toward foreign investment in order to prevent against risks from the movement of goods and capital. According to Cohen and Zysmann (1987), many companies became convinced, wrongly in the opinion of many, that production could easily be transferred to other independent companies based on the differentials between internal and external production costs, without any loss of control over the capacity to compete. Precisely with reference to the cost of production as the sole, or prevalent decision-making criterion, many observers view offshoring and outsourcing as a genial solution to the cost differentials with emerging countries. Along with the advantages it brings, global sourcing also has important disadvantages that operators and researchers view in a different way. The most obvious disadvantage derives from the complexity in the management of contracts and from the differences among the partners in terms of traditions, culture, and values.

Some observers even think that the outsourcing of production processes is behind the lower weight of this function in the value chain. Responding to the challenges from global competition by forming alliances with suppliers can represent an effective response, but in the long run there is no guarantee that this strategy can always be repeated with the same positive results.

\section{Risks and Future Perspectives}

Researchers are unanimous in recognizing that there are many obstacles to adopt long-term outsourcing and offshoring strategies. The areas most mentioned in this regard are the following: (1) As far as labour is concerned, the unions are opposed to outsourcing in principle; (2) many firms have difficulty in defining what their core competencies are and what it is an outside supplier is better at doing than they are; (3) the success of an outsourcing strategy also depends on the competence of the supplier's management; and (4) many firms fear 
the risk of losing control over their intellectual property or seeing this eroded. Quinn and Hilmer (1994) had classified three types of strategic risks the firm faces when outsourcing: loss of critical capacity or critical competencies, weakening of the capacity to coordinate more than one function, and loss of control over the supplier. When the firm gives up a component to outsourcing, it also transfers the technological knowledge to produce it, thus running an initial risk: In fact, there is no assurance that the supplier can update or improve the activity. As a result, the firm could lose the capacity to remain or return competitive, and at the same time old and new competitors might have the chance to catch up, since they, too, can turn to the supplier. The firm can also lose its strategic capacity to innovate regarding products and production processes. Suppliers do not always undertake cutting edge $\mathrm{R} \& \mathrm{D}$, nor have the capacity to interpret the expectations of the final users. Outsourcing often means dismantling or transferring organizational structures, which are then difficult to reconstruct if, in order to do so, certain activities must be started up again internally. Quinn and Hilmer (1994) suggested a dual strategy that consists in not fully transferring a function but maintaining its critical activities within the firm (in particular the capacity to innovate), only transferring the less important activities, those which any firm could acquire. Carrying out an activity internally means exchanging know-how among several of the firm's functions, which can give rise to or consolidate new ideas about products or processes. An excessive dependence on outside suppliers creates difficulties in generating know-how and spreading this among various functions. Clark and Fujimoto (1990), in particular, are in agreement about this risk. The firm can avoid this risk by maintaining close contact with its suppliers. A lot depend on the number of suppliers: If they are numerous, there is a substantial reduction in the possibility for an effective coordination. The first form of loss of control occurs when the supplier has information on the technologies, strategic choices or tactics of the outsourcer and uses this to its own advantage. A situation can develop in which one or more suppliers use this knowledge against the interests of the firm that has outsourced activities to them (Bragg, 2006; Quinn \& Hilmer, 1994). Contractual clauses are not enough to defend against this. Some firms maintain ownership of the equipment and production facilities the outsourcer uses. In cases of conflict, they can block the use of this equipment or shut down the entire production line. The second form of loss of control arises when the supplier cannot provide the agreed upon quality or quantities; this situation emerges when there is no time left to take corrective measures. The risk involves the loser of market share, which is always difficult to regain. This risk is high when there is a lack of continual information on the supplier's activities. The risks which have been mentioned are the most obvious ones, though not the only ones. A particular risk regards the internal capacities of the firm. There is a risk that the firm may lose crucial capacities for thinking up and developing new products. This is especially true for firms whose main competitive advantage lies in product innovation. These capacities are generally the result of experience and group work. Transferring these capacities and working groups to a supplier can represent a serious loss. The risk is even greater, if the supplier uses the acquired know-how and capacities to compete with the outsourcer. This is not necessarily fraudulent behaviour. The supplier can gain an advantage from working for more than one outsourcer; it can grow and find its own niche. To reduce this risk, the firm must maintain control over product and process innovation that provides a sustainable long-term competitive advantage which is unique and distinct; it should transfer those activities that can be easily imitated. The non-competition clause in contracts is not enough to defend firms from this risk. The supplier could transfer the acquired know-how to the outsourcer's competitor. For this risk as well, it is not always a question of condemnable behaviour. The supplier could be taken on (in the case of a vertical integration strategy) by a competitor of the outsourcer, who would thus legitimately acquire information. One defence against this is to 
introduce contract clauses that require the restitution of information at the end of the project or when there is consensual rescission of the contract. However, this defence is not entirely effective, since the know-how becomes part of the patrimony of individuals and of the entire organization. Another large risk from outsourcing concerns the workforce, which fears (often justifiably) the loss of jobs. Quinn (1999) warned that outsourcing can also lead to a worsening in the social climate within a firm, which in turn can cause a worsening in performance. In recent years, the economic crisis in the United States and Europe has led to many reflections.

An opposite phenomenon is catching on. Some researches found that many companies in United States are considering to re-shore production from Asia (Garza, 2013; Davidson, 2010), in particular in these sectors: appliances and electrical equipment, computers and electronics, transportation products, plastics and rubber, heavy machinery (The Boston Consulting Group, 2012). The re-shoring refers to the decision regarding the location of an organization's activities and specifically in the movement of economic activity that had previously been performed in a foreign country shifting to a domestic setting (Garza, 2013). This phenomenon is spreading also in Europe even if European companies were much less involved in the offshoring strategy compared to the transnational American companies. According to Tate, Ellram, Schoenherr, and Petersen. (2014), the main factors that influence the re-shoring decision are: labour costs, energy cost, skilled labour, taxes, currency exchange, transportation, and freight. Garza (2013) identified the following ranking of factors that influence the re-shoring decisions: (1) the increasing wages of the local workers as the first reason (recently, the wages in China have been significantly increasing), (2) the shipping costs that are related to the increasing price of diesel fuel, (3) the inventory costs, (4) the quality control cost, and (5) the prototyping expenditures.

\section{Conclusions}

To decide whether or not to pursue an outsourcing strategy, it is necessary to determine if this will lead to a long-term sustainable competitive advantage with respect to carrying out these activities internally. Management must focus attention on the core competencies and those areas in which the firm can develop a competitive advantage, transferring the other activities to several suppliers that are better able to carry these out. Thus outsourcing becomes one of the most effective options. Offshoring and global sourcing have contributed to the birth and growth of many companies that have achieved leading positions in world markets. With the very rapid economic growth of China, India, Russia, and Brazil (BRIC) and other countries and the consequent increase in the demand of the middle class of these countries (while demand languished in the countries of the West), the potential of these enterprises is greatly increased. However, at the same time, global sourcing and offshoring have also been heavily criticized by governments (the U.S. and Europe in particular) as recognized as a cause of further weakening national economies.

Recently the governments are focused on keeping the national economies strong and stable, increasing workplaces, supporting enterprise, and raising innovation and productivity in business. In order to improve national competitiveness, scholars and economists are looking for solutions. Porter, Rivkin, and Kanter (2013) proposed actions such as: increasing sourcing from local suppliers, mentoring local suppliers, and bringing offshored activities back. Some studies and research found that the large multinational corporations, mainly in the United States, are moving their production back or considering it such a strategic decision in the near future. So what is the future for offshoring and global sourcing? Probably, as in the past, firms will be inevitably 
driven by the search for profit and value creation (Pellicelli, 2007) even if attempting to ensure the quality to consumers. However, the well-known risks and disadvantages of offshoring strategies may lead companies to pay greater attention to the maintenance of jobs and increase of agreements and cooperation with local suppliers, to the detriment of suppliers across the border, in order to promote the domestic economy. So this could cause a sort of rebalancing to major social responsibility towards their stakeholders, employees, and suppliers in foreground and the country of origin.

\section{References}

Bragg, S. M. (2006). Outsourcing: A guide to selecting the correct business unit, negotiating the contract, and maintaining control of the process. New York: Wiley.

Chalos, P. (1995). Costing, control and strategic analysis in outsourcing decisions. Journal of Cost Management, 4, 31-37.

Clark, K. B., \& Fujimoto, T. (1990). The power of product integrity. Harvard Business Review, 68(6), 107-118.

Cohen, S., \& Zysmann, J. (1987). Manufacturing matters. New York: Basic Books Inc..

Dalla Chiara, B., \& Pellicelli M. (2010). Role of intermodality in global sourcing and offshore outsourcing: Maritime transport and new rail connections between Europe and Asia. Oviedo: SP.

Dalla Chiara, B., \& Pellicelli M. (2011). On the cost of road-rail combined transport/Sul costo del trasporto combinato strada rotaia. Ingegneria Ferroviaria, 66, 951-965.

Dalla Chiara, B., Pellicelli, M., \& De Bonis, L. (2012). The railway connections in the new Europe-Asia economic relationships/Le connessioni ferroviarie nelle nuove relazioni economiche Europa-Asia. Ingegneria Ferroviaria, 67(3), 249-272.

Davidson, P. (2010). Some manufacturing head back to USA. The New York Times. Retrieved from http://www.usatoday.com/money/economy/2010-08-06-manufacturing04_CV_N.htm\#

Garza, F. A. (2013). International business locations: A framework and model entrepreneurial "reshoring". Proceedings from Annual Conference of the Academy of International Business, pp. 11-12.

Kotabe, M., \& Helsen, K. (1998). Global marketing management. New York: John Wiley \& Sons.

Mella, P. (2007). Selfish orgonic networks. International Journal of Knowledge, Culture and Management, 6(7), 139-155.

Pellicelli, M. (2006). The new economics of outsourcing: Empirical evidence from the textile-apparel industry. Retrieved from www.ea2000.it

Pellicelli, M. (2007). Creazione di valore e Value Based Management. Turin: Giappichelli (Monograph).

Pellicelli, M. (2009a). L'outsourcing e l'offshoring nell'economia dell'impresa. Turin: Giappichelli (Monograph).

Pellicelli, M. (2009b). From outsourcing to offshoring and virtual organizations. How management is redefining corporate boundaries. International Journal of Knowledge, Culture and Change Management, 9(7), 77-88.

Porter, M. E., Rivkin, J. W., \& Kanter, R. M. (2013). Competitiveness at a crossroads. Boston: Harvard Business School.

Quinn, J. B. (1999). Strategic outsourcing: Leveraging knowledge capabilities. Sloan Management Review, 2, 9 -21.

Quinn, J. B., \& Hilmer, F. G. (1994). Strategic outsourcing. Sloan Management Review, 35, 43-55.

Roodhooft, F., \& Warlop, L. (1999). On the role of sunk costs and asset specificity in outsourcing decisions: A research note. Accounting, Organization and Society, 24, 363-369.

Tate, W. L., Ellram, L. M., Schoenherr, T., \& Petersen, K. J. (2014). Global competitive conditions driving the manufacturing location decision. Business Horizons, 57(3), 1-10.

The Boston Consulting Group. (2012). More than a third of large manufacturers are considering reshoring from China to the U.S.. Retrieved from http://www.bcg.com/media/PressReleaseDetails.aspx?id=tcm:12-104216

Williamson, O. (1989). Transaction cost economics. In R. Schmalensee, \& R. Willig (Eds.), Handbook of industrial organization (pp. 136-181). Amsterdam: Elsevier. 